University of Nebraska - Lincoln

DigitalCommons@University of Nebraska - Lincoln

\title{
Operational MERIS-based NIR-red algorithms for estimating chlorophyll-a concentrations in coastal waters - The Azov Sea case study
}

\author{
Wesley J. Moses \\ National Research Council/Naval Research Laboratory, wesley.moses.ctr.in@nrl.navy.mil \\ Anatoly A. Gitelson \\ University of Nebraska at Lincoln, agitelson2@unl.edu \\ Sergey Berdnikov \\ Southern Scientific Center of the Russian Academy of Sciences, berdnikov@ssc-ras.ru \\ Vladislav Saprygin \\ Southern Scientific Center of the Russian Academy of Sciences, saprygin@ssc-ras.ru \\ Vasily Povazhnyi \\ Southern Scientific Center of the Russian Academy of Sciences, povazhny@mmbi.krinc.ru
}

Follow this and additional works at: https://digitalcommons.unl.edu/natrespapers

Part of the Natural Resources and Conservation Commons

Moses, Wesley J.; Gitelson, Anatoly A.; Berdnikov, Sergey; Saprygin, Vladislav; and Povazhnyi, Vasily, "Operational MERIS-based NIR-red algorithms for estimating chlorophyll-a concentrations in coastal waters - The Azov Sea case study" (2012). Papers in Natural Resources. 357.

https://digitalcommons.unl.edu/natrespapers/357

This Article is brought to you for free and open access by the Natural Resources, School of at DigitalCommons@University of Nebraska - Lincoln. It has been accepted for inclusion in Papers in Natural Resources by an authorized administrator of DigitalCommons@University of Nebraska - Lincoln. 


\title{
Operational MERIS-based NIR-red algorithms for estimating chlorophyll-a concentrations in coastal waters - The Azov Sea case study
}

\author{
Wesley J. Moses a , Anatoly A. Gitelson ${ }^{\mathrm{b}, *}$, Sergey Berdnikov ${ }^{\mathrm{c}}$, Vladislav Saprygin ${ }^{\mathrm{c}}$, Vasily Povazhnyi ${ }^{\mathrm{c}}$ \\ a National Research Council/Naval Research Laboratory, Washington, D.C., USA \\ b Center for Advanced Land Management Information Technologies (CALMIT), University of Nebraska-Lincoln, USA \\ c Southern Scientific Center of the Russian Academy of Sciences, Rostov-on-Don, Russia
}

\section{A R T I C L E I N F O}

\section{Article history:}

Received 12 October 2011

Received in revised form 26 January 2012

Accepted 29 January 2012

Available online 23 February 2012

\section{Keywords:}

Remote sensing

Chlorophyll- $a$

Turbid productive waters

NIR-red

MERIS

Operational algorithms

\begin{abstract}
A B S T R A C T
We present here results that strongly support the use of MERIS-based NIR-red algorithms as standard tools for estimating chlorophyll- $a$ (chl-a) concentration in turbid productive waters. The study was carried out as one of the steps in testing the potential of the universal applicability of previously developed NIR-red algorithms, which were earlier calibrated using a limited set of MERIS imagery and in situ data from the Azov Sea and the Taganrog Bay, Russia, and data that were synthetically generated using a radiative transfer model. We used an extensive set of MERIS imagery and in situ data collected over a period of three years in the Azov Sea and the Taganrog Bay for this validation task. We found that the two-band and three-band NIR-red algorithms gave consistently highly accurate estimates of chl-a concentration, with a mean absolute error of $4.32 \mathrm{mg} \mathrm{m}^{-3}$ and $4.71 \mathrm{mg} \mathrm{m}^{-3}$, respectively, and a root mean square error as low as $5.92 \mathrm{mg} \mathrm{m}^{-3}$, for data with chl- $a$ concentrations ranging from $1.09 \mathrm{mg} \mathrm{m}^{-3}$ to $107.82 \mathrm{mg} \mathrm{m}^{-3}$. This obviates the need for case-specific reparameterization of the algorithms, as long as the specific absorption coefficient of phytoplankton in the water does not change drastically, and presents a strong case for the use of NIR-red algorithms as standard algorithms that can be routinely applied for near-real-time quantitative monitoring of chl- $a$ concentration in the Azov Sea and the Taganrog Bay, and potentially elsewhere, which will be a real boon to ecologists, natural resource managers and environmental decision-makers.
\end{abstract}

(c) 2012 Elsevier Inc. All rights reserved.

\section{Introduction}

The dire environmental importance of regularly monitoring the biophysical status of estuarine and coastal waters is well established (e.g., Carmichael, 1997; Revenga \& Kura, 2003). The concentration of chlorophyll- $a$ (chl- $a)$ - a photosynthetically active pigment in phytoplankton - in water is a key indicator of the biophysical status of a water body (e.g., Falkowski \& Raven, 1997; Falkowski et al., 2000; Honeywill et al., 2002; Schalles et al., 1998). Compared to open ocean waters, most estuarine and coastal waters are optically complex due to the high concentrations of suspended sediments and colored dissolved organic matter (CDOM) in addition to phytoplankton (Morel \& Prieur, 1977), which complicates the estimation of chl- $a$ concentration (e.g., Carder et al., 2004; Dall'Olmo et al., 2005; Darecki \& Stramski, 2004; Gitelson, 1992; Gons, 1999). Nevertheless, several algorithms that use reflectances in the red and near infrared (NIR) regions have been developed and shown to yield accurate estimates of chl- $a$ concentration in turbid productive estuarine and

\footnotetext{
* Corresponding author. Tel.: +1 402472 8386; fax: +1 4024722946.

E-mail addresses: wesley.moses.ctr.in@nrl.navy.mil (W.J. Moses),

agitelson2@unl.edu (A.A.Gitelson), berdnikov@ssc-ras.ru (S. Berdnikov), saprygin@ssc-ras.ru (V. Saprygin), povazhny@mmbi.krinc.ru (V. Povazhnyi).
}

coastal waters (e.g., Dall'Olmo \& Gitelson, 2005; Dekker, 1993; Gitelson, 1992; Gitelson \& Kondratyev, 1991; Gitelson et al., 2011a; Gons, 1999; Gower et al., 1999; Gurlin et al., 2011; Han \& Rundquist, 1997; Le et al., 2009; Moses et al., 2009a, 2009b; Ruddick et al., 2001; Stumpf \& Tyler, 1988; Vasilkov \& Kopelevich, 1982; Yang et al., 2010). The parameters of most of these algorithms were empirically set by comparing remotely sensed data with in situ measured data from a particular geographical and/or seasonal regime and their validity is often confined to that geographical and/or seasonal regime. This often entails reparameterization of the algorithms for different water bodies. The need for reparameterization is a measure of the ability or the lack thereof of the algorithms to handle variations in the biophysical characteristics of turbid productive waters across various geographical and/or seasonal regimes. In addition, for applications involving airborne or spaceborne remotely sensed data, the lack of a robust atmospheric correction program that performs consistently well will also contribute to the need for reparameterization. However, for effective near-real-time quantitative remote monitoring of chl- $a$ concentration, it is necessary that the algorithms be fully operational without the need for reparameterization.

Moses et al. (2009b), using a limited dataset, demonstrated that two-band and three-band NIR-red algorithms can yield accurate estimates of chl- $a$ concentration in the Azov Sea and the Taganrog Bay 
using remotely sensed reflectance data from MERIS (MEdium Resolution Imaging Spectrometer). They showed that the parameters of the algorithms set based on the limited MERIS dataset from the Azov Sea and the Taganrog Bay closely matched the parameters of the NIR-red algorithms developed based on an extensive dataset collected using field spectrometers in several turbid productive lakes in Nebraska, USA (Gitelson et al., 2009, 2011a; Gurlin et al., 2011). Moses (2009) found that the NIR-red algorithms did not need to be reparameterized for limited datasets from the Chesapeake Bay and Lake Kinneret, Israel. Yacobi et al. (2011) also reached a similar conclusion when using the NIR-red algorithms for estimating chl- $a$ concentration in Lake Kinneret. Gilerson et al. (2010) showed that the NIR-red algorithms based on the limited dataset from the Azov Sea and the Taganrog Bay gave accurate estimates of chl- $a$ concentration when applied to a large number of synthetically generated reflectance spectra, and developed advanced versions of the NIR-red algorithms. Gilerson et al. (2010) also showed that the slope parameter of the NIR-red algorithms is affected by the specific absorption coefficient of phytoplankton $\left(a_{p h}{ }^{*}\right)$. These results form the basis for our continued attempts to test the limits of the potential of NIR-red algorithms to be routinely applied in an operational manner to estimate chl- $a$ concentrations from near-real-time satellite data from turbid productive waters from around the globe without the need for case-specific reparameterization of the algorithms.

In this study, we have applied NIR-red algorithms calibrated previously using a limited set of satellite data from the Azov Sea and the Taganrog Bay (Moses et al., 2009b), and also advanced versions of NIR-red algorithms developed using synthetically generated data (Gilerson et al., 2010), to an extensive dataset collected from the Azov Sea and Taganrog Bay over a period of three years. It is noteworthy that these NIR-red algorithms are based on the spectral channels of MERIS. We have compared the estimation accuracy of the NIR-red algorithms with that of the standard MERIS chl- $a$ product for Case II waters. The accuracy yielded by the MERIS-based algorithms was further evaluated by comparison with data from a single image from the spaceborne hyperspectral sensor, HICO (Hyperspectral Imager for the Coastal Ocean). If the MERIS-based NIR-red algorithms are found to yield consistently highly accurate estimates of chl- $a$ concentration for this extensive dataset, a strong case can be made for using these algorithms in tandem with MERIS data in an operational manner for quantitative near-real-time monitoring of the Azov Sea and the Taganrog Bay, which will be a valuable asset to ecologists, natural resource managers and environmental decision-makers of this region. Such an outcome will provide impetus for similar studies on other turbid productive water bodies around the world, which will involve observing the variations in $a_{p h}{ }^{*}$ among water bodies and analyzing the sensitivity of the NIR-red algorithms to variations in $a_{p h}{ }^{*}$.

\section{Data and methods}

The Azov Sea is a shallow inland sea adjoined by Ukraine on the west and Russia on the east (Fig. 1). The Taganrog Bay is on the northeastern part of the Azov Sea. The Azov Sea is connected to the Black Sea through the Kerch Strait. However, the Azov Sea gets most of its water input from the runoff from the Don River, the Kuban River, and several smaller rivers. The sea is very shallow, with a maximum depth of only $9 \mathrm{~m}$ (Borysova et al., 2005). The fresh water inflow from fluvial runoff comprises more than $10 \%$ of the volume of water in the sea (Matishov, 2005). Thus, the water quality of the Azov Sea is heavily influenced by the fluvial runoff. The watershed area of the Azov Sea basin has undergone tremendous industrialization in the last couple of decades, and consequently, the fluvial runoff into the Azov Sea is replete with industrial effluents (Matishov, 2005). The increased influx of terrigenous nutrients has produced significant eutrophication in the Azov Sea. This has contributed to drastic changes in the ecosystem, resulting in tremendous loss of fish population,

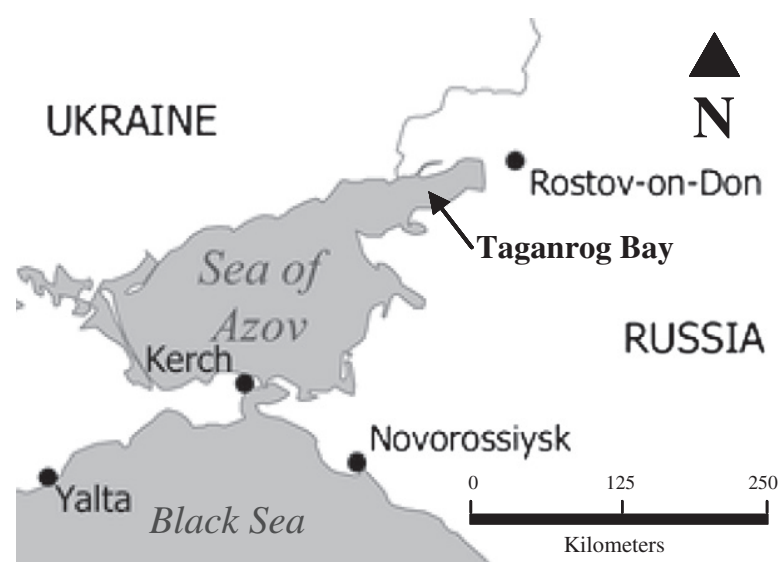

Fig. 1. Map of the Azov Sea and the surrounding region (modified from http:// commons.wikimedia.org).

which has hurt the local economy (Leppäkoski et al., 2009). Efforts have been undertaken in recent years to implement an integrated watershed management plan to monitor and regulate the water quality in the Azov Sea.

In situ data were collected during 18 campaigns on the Azov Sea and the Taganrog Bay between the months of March and October over a period of three years, from 2008 to 2010, by the crew at the Southern Scientific Center of the Russian Academy of Sciences, Rostov-on-Don, Russia. Water samples collected at each station were filtered through Whatman GF/F glass filters. Chl- $a$ was extracted from the filters with hot ethanol and its concentration was quantified spectrophotometrically based on the method described by Jeffrey and Humphrey (1975).

Full resolution ( $260 \mathrm{~m} \times 290 \mathrm{~m}$ ) level-2 MERIS images acquired on the date of in situ data collection were available for most dates. In a few cases when a MERIS image was not available for the date of in situ data collection, images acquired up to two days before or after the date of in situ data collection were used. The level-2 MERIS images were already atmospherically corrected by the European Space Agency's automatic data processing system. The pixels corresponding to the stations from the 18 campaigns were all identified as sedimentloaded case 2 water pixels and subjected to the Bright Pixel Atmospheric Correction procedure (Aiken \& Moore, 2000; Moore et al., 1999).

MERIS-based NIR-red algorithms that were previously calibrated using a limited dataset from the Azov Sea and Taganrog Bay (Moses et al., 2009b) were,

Two-band MERIS NIR-red algorithm:

Chl- $a=61.324\left[R_{665}^{-1} \times R_{708}\right]-37.94$

Three-band MERIS NIR-red algorithm:

Chl- $a=232.29\left[\left(R_{665}^{-1}-R_{708}^{-1}\right) \times R_{753}\right]+23.174$

where $R_{X}$ is the remote sensing reflectance in the spectral band centered at $x \mathrm{~nm}$. These two-band and three-band algorithms are henceforth referred to as 2009NR02 and 2009NR03, respectively, in this paper.

Using reflectances generated synthetically by the radiative transfer model, Hydrolight (Mobley, 1989, 1994; Mobley \& Sundman, 2008), Gilerson et al. (2010) reformulated the two-band and threeband NIR-red models in terms of the absorption and scattering coefficients of the constituents, namely, water, phytoplankton, non-algal particles, and CDOM. They investigated the sensitivity of the NIRred models to variations in the absorption and scattering coefficients of the constituents and concluded that, (i) the absorption coefficient 
of water $\left(a_{w}\right)$ is the most influential factor, (ii) the chl- $a$ specific absorption coefficient of phytoplankton $\left(a_{p h}{ }^{*}\right)$ affects the slope of the relationship between the model values and chl- $a$ concentrations, and (iii) the NIR-red models are not very sensitive to variations in the absorption by CDOM and back-scattering by non-algal particles. Using values taken from the literature for $\left(a_{w}\right)$ and determining $a_{p h}{ }^{*}$ from a large set of synthetic and actually measured data, Gilerson et al. (2010) formulated advanced versions of the two-band and threeband NIR-red algorithms as follows:

Advanced two-band MERIS NIR-red algorithm:

Chl- $a=\left[35.75 \times\left(R_{665}^{-1} \times R_{708}\right)-19.3\right]^{1.124}$

Advanced three-band MERIS NIR-red algorithm:

Chl- $a=\left[113.36 \times\left\{\left(R_{665}^{-1}-R_{708}^{-1}\right) \times R_{753}\right\}+16.45\right]^{1.124}$

These advanced two-band and three-band NIR-red algorithms are henceforth referred to as AdvNR02 and AdvNR03, respectively, in this paper.

\section{Results and discussion}

Atmospherically corrected remote sensing reflectances were extracted from the MERIS images for all stations in the in situ dataset. Out of all the stations where in situ data were collected, the stations that met the following criteria (Moses et al., 2009b) were selected for analysis.

(i) The station is at least at a two-pixel distance from the shoreline.

(ii) The station is on a cloud/haze-free pixel in an image acquired within two days before/after the date of in situ data collection.

(iii) The atmospheric correction procedure did not produce reflectance spectrum with negative reflectances beyond $443 \mathrm{~nm}$.

(iv) The reflectance spectrum is neither spurious nor inconsistent in its spectral shape with the observed in situ data.

Pixels with negative reflectances beyond $443 \mathrm{~nm}$ were less common compared to those with positive reflectances and seemed to occur mostly on images with significant cloud cover. Pixels with spurious reflectances were also almost always associated with images with significant cloud cover or cloudy neighboring pixels. An individual reflectance spectrum was deemed inconsistent in its spectral shape (in the red and NIR regions) with the observed in situ data only after comparison with several reflectance spectra from stations having similar constituent concentrations. An example of such an inconsistent spectrum has been previously illustrated (see Fig. 1 in Moses et al., 2009b). Such inconsistent spectra could be due to (i) an actual change in the chl-a concentration in water between the time of in situ data collection and satellite data acquisition, (ii) high spatial heterogeneity of the water, which results in the point in situ measurement being not representative of the area covered by the satellite pixel around the station, or (iii) inaccurate atmospheric correction. In any case, such inconsistent spectra are difficult and virtually impossible to identify without the aid of actual field data or reliable knowledge of the field conditions, and thus they pose inherent hurdles to calibrating and validating satellite-based algorithms than can be applied operationally without the aid of field data. Nevertheless, such inconsistent spectra comprised only about $10 \%$ of the whole dataset.

113 stations met the aforementioned criteria. The minimum, maximum, median, and mean values of in situ measured chl- $a$ concentration for these 113 stations were, 1.09, 107.82, 22.39, and $31.74 \mathrm{mg} \mathrm{m}^{-3}$, respectively.

\subsection{Estimation of chl-a concentration}

The NIR-red algorithms, 2009NR02 (Eq. 1), 2009 NR03 (Eq. 2), AdvNR02 (Eq. 3), and AdvNR03 (Eq. 4) were applied to remote sensing reflectances from the 113 stations, and the estimated chl- $a$ concentrations were compared with the chl- $a$ concentrations measured in situ. All four algorithms yielded remarkably accurate estimates of chl- $a$ concentration (Figs. 2 and 3), with very low magnitudes of the root mean square error (RMSE) and the mean absolute error (MAE). AdvNR02 had the lowest MAE of $4.32 \mathrm{mg} \mathrm{m}^{-3}$. AdvNR03 had a slightly higher MAE. AdvNR02 and AdvNR03 had virtually the same RMSE. 2009NR02 and 2009NR03 had slightly higher RMSEs and MAEs compared with AdvNR02 and AdvNR03 but were still quite low.

The NIR-red algorithms performed much better than the standard neural-network-based algorithm, algal_2 (Doerffer \& Schiller, 2007; Schiller \& Doerffer, 1999), used for estimating chl-a concentration in case II waters from MERIS data (Fig. 4). The chl-a concentrations retrieved from algal_2 were severely underestimated, especially at chl- $a$ concentrations above $50 \mathrm{mg} \mathrm{m}^{-3}$, which is not surprising considering the fact that the neural network was trained for only chl- $a$ concentrations below $50 \mathrm{mg} \mathrm{m}^{-3}$ (Doerffer \& Schiller, 2007; Schiller \& Doerffer, 1999).

As demonstrated by Gilerson et al. (2010), the slope of the relationship between the NIR-red model values and chl- $a$ concentrations is affected by $a_{p h}{ }^{*}$. The remarkable consistency of the NIR-red algorithms across data collected over a period of three years with a wide range of chl- $a$ concentrations suggests that $a_{p h}{ }^{*}$ had not changed significantly in the Azov Sea and Taganrog Bay during this three-year period, and it further demonstrates the potential of these algorithms to be used as tools for near-real-time quantitative monitoring of chl- $a$ concentration in the Azov Sea and Taganrog Bay.
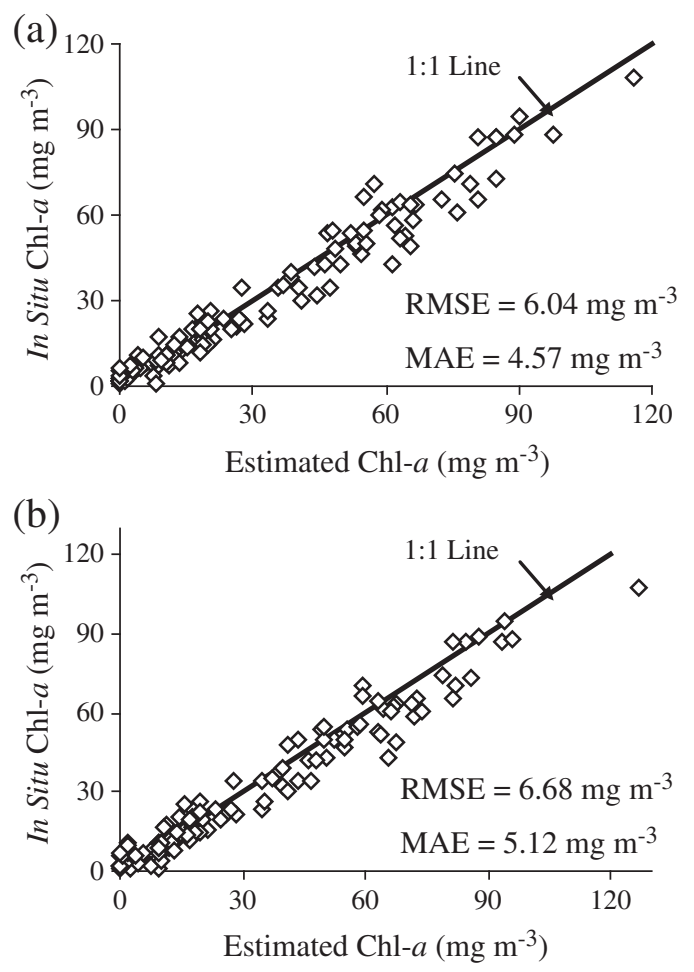

Fig. 2. Comparisons of chl- $a$ concentrations measured in situ with chl- $a$ concentrations estimated by (a) the two-band NIR-red algorithm, 2009 NR02 (Eq. 1) and (b) the threeband NIR-red algorithm, 2009 NR03 (Eq. 2), which were previously calibrated using a limited dataset from the Azov Sea and the Taganrog Bay (Moses et al., 2009b). 
(a)
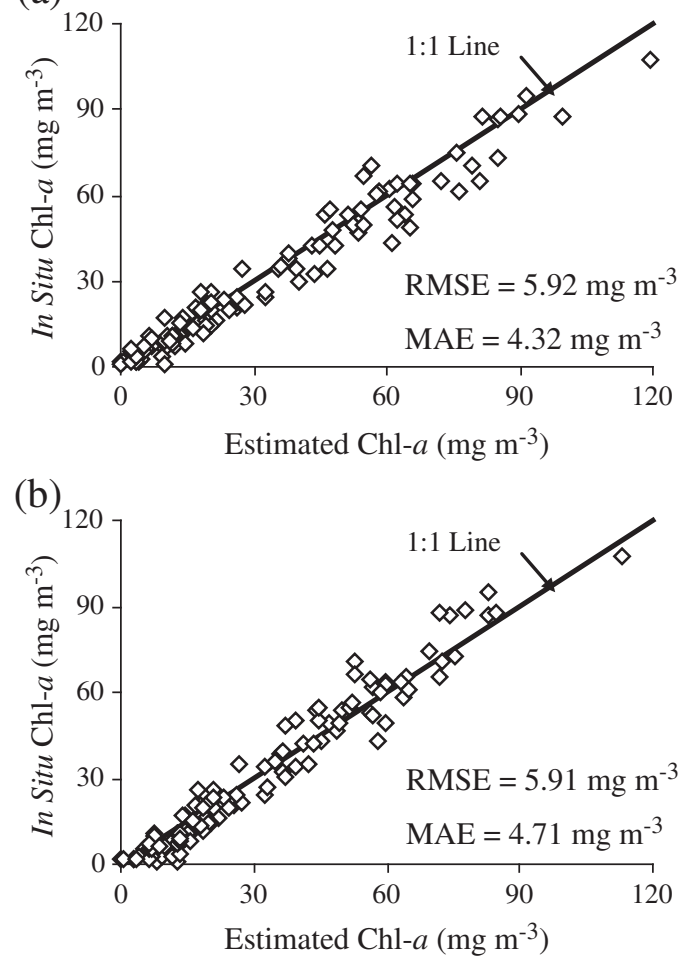

Fig. 3. Comparisons of chl- $a$ concentrations measured in situ with chl- $a$ concentrations estimated by advanced versions (Gilerson et al., 2010) of (a) the two-band NIR-red algorithm, AdvNR02 (Eq. 3) and (b) the three-band NIR-red algorithm, AdvNR03 (Eq. 4).

Fig. 5 contains chl- $a$ maps produced using the 2009NR02 algorithm for the Azov Sea and Taganrog Bay for 03 Sep 2008 and 02 Oct 2008. The spatial variation of chl- $a$ concentration within the
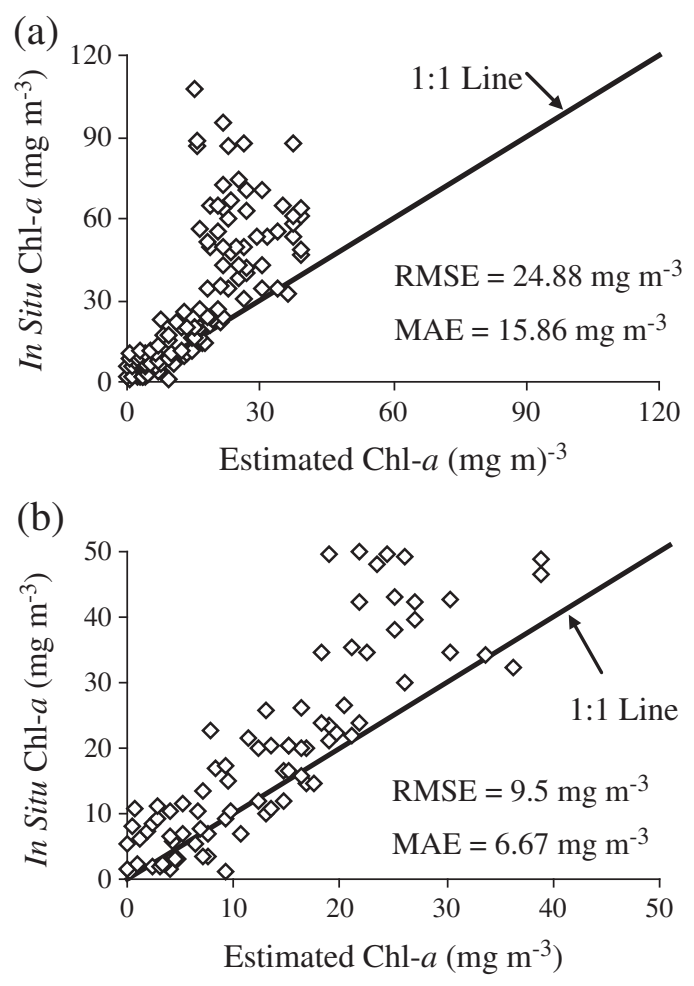

Fig. 4. Comparison of chl- $a$ concentrations measured in situ with chl- $a$ concentrations estimated by the standard MERIS chl- $a$ algorithm (algal_2) (a) for the whole range of chl- $a$ concentrations and (b) for chl- $a$ below $50 \mathrm{mg} \mathrm{m}^{-3}$. area for each date and the temporal variation between the two dates are captured well by the algorithm. As expected, the chl- $a$ concentration is significantly lower on 02 Oct 2008 than on 03 Sep 2008, especially in the Taganrog Bay region, due to the lower water temperature caused by the approaching winter.

\subsection{Comparison with hyperspectral data}

HICO is a spaceborne hyperspectral sensor designed specially for studying the coastal systems (Korwan et al., 2010; Lucke et al., 2011). The sensor operates within the spectral range of 350$1080 \mathrm{~nm}$, with contiguous spectral channels at $5.73 \mathrm{~nm}$ spectral resolution (Lucke et al., 2011). Gitelson et al. (2011b) used data from a HICO image acquired on 13 July 2010 to estimate chl- $a$ concentrations in eight stations in the Azov Sea and Taganrog Bay where in situ data were collected during 13-15 July 2010. They took advantage of the fine-resolution hyperspectral data to spectrally tune the NIR-red algorithms and determined that the optimal spectral bands for the three-band model were located at $\lambda_{1}=684 \mathrm{~nm}, \lambda_{2}=700 \mathrm{~nm}$, and $\lambda_{3}=720 \mathrm{~nm}$. The NIR-red model with these optimal spectral bands was able to explain more than $85 \%$ of the variation in chl- $a$ concentration at the eight stations (Gitelson et al., 2011b). Of these eight stations, valid MERIS reflectances were available for four stations. For these four stations, the MERIS-based NIR-red models had as close a relationship with chl- $a$ concentration as did the optimized HICObased NIR-red model (Fig. 6). The HICO-based two-band NIR-red model values were derived using HICO bands that were closest to the MERIS bands. The determination coefficient for linear regression was 0.98 for the MERIS-based two-band and three-band models compared with 0.91 and 0.92 , respectively, for the HICO-based two-band and three-band NIR-red models. The differences between the slopes of the linear regression for the MERIS-based and HICO-based NIRred models is a function of various factors, chief of which is the difference in the retrieval of at-surface reflectances. MERIS data were atmospherically corrected using the Bright Pixel Atmospheric Correction, whereas HICO data were atmospherically corrected using ATREM (ATmospheric REMoval; Gao \& Davis, 1997).

Though a dataset with just four stations is too limited to permit a comprehensive conclusion, the excellent performance of the MERISbased NIR-red models on a par with the HICO-based NIR-red models still demonstrates the sufficiency of MERIS-based NIR-red models for reliably and accurately estimating chl- $a$ concentration in turbid productive waters. MERIS spectral channels centered at $665 \mathrm{~nm}$, $708 \mathrm{~nm}$, and $753 \mathrm{~nm}$, with spectral resolutions of $10 \mathrm{~nm}, 10 \mathrm{~nm}$, and $7.5 \mathrm{~nm}$, respectively, seem adequate for reliable quantitative estimation of chl- $a$ concentration in turbid productive waters.

Even though finer spectral resolution might be desirable for more optically complex waters, narrower spectral bands come at the cost of low signal-to-noise ratio (SNR) because each detector would receive fewer photons due to the narrower width of the spectral band. Lower SNR produces a significant detrimental effect on the accuracy of chl- $a$ retrieval (e.g. Moses et al., 2012). Levin et al. (2005) found that when noise issues are considered, a sensor with 28 channels yields a retrieval accuracy that is similar to or even slightly better than that of a 54-channel sensor with half the spectral resolution.

\section{Conclusion}

The results present a strong case for using the MERIS-based NIRred algorithms as standard tools for estimating chl- $a$ concentration in the Azov Sea and the Taganrog Bay region, without the need for reparameterization of the algorithms. This will be a great asset for near-real-time remote monitoring of this ecologically sensitive region.

The spectral locations and resolutions of the NIR and red channels of MERIS seem adequate enough to capture the spectral variations in 

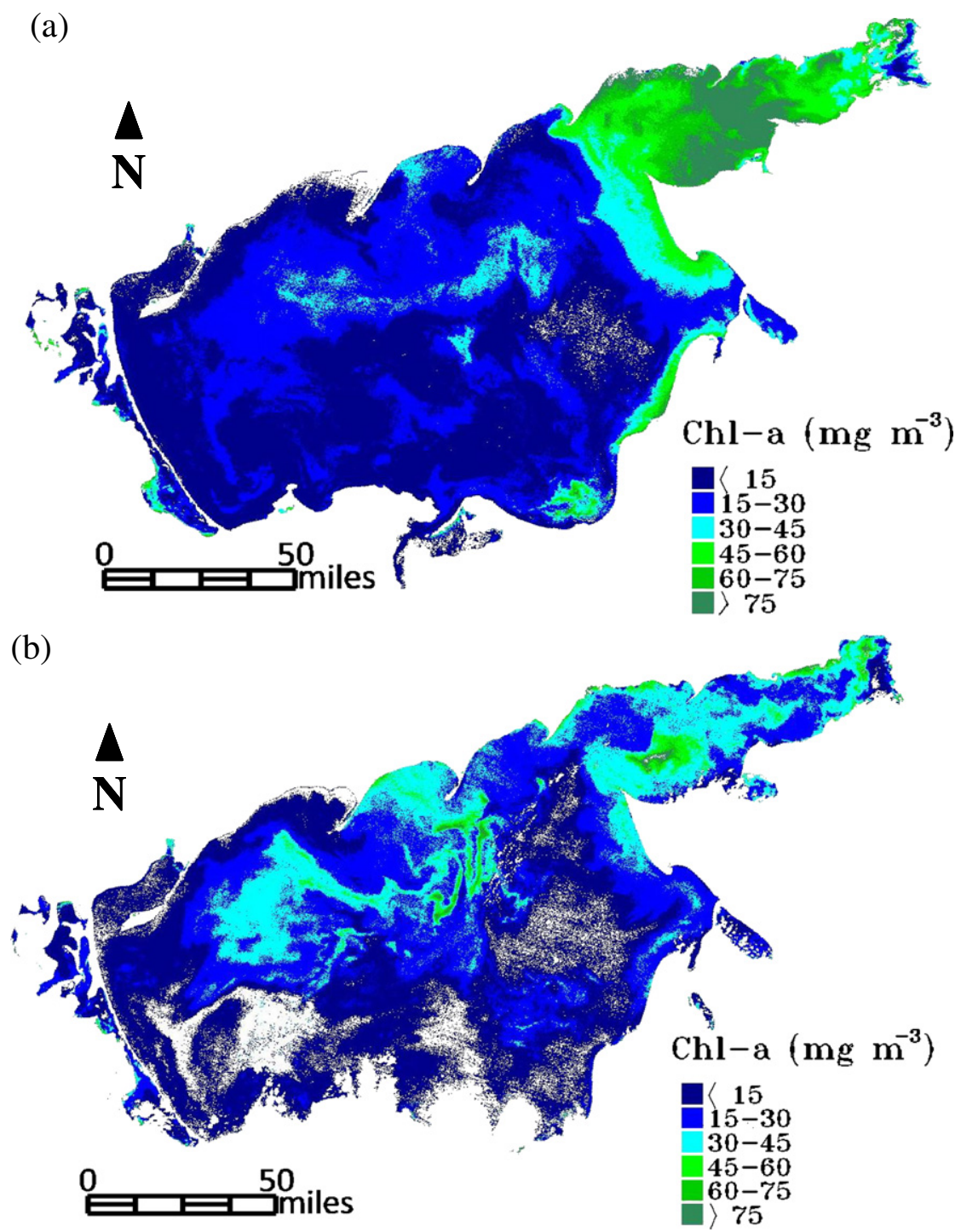

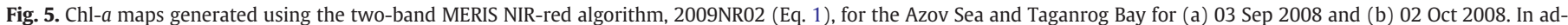
dition to the spatial variation of chl- $a$ concentration on each date, the maps also illustrate the temporal variations.

reflectance from optically complex turbid productive waters due to changes in chl- $a$ concentration. At least for the range of chl- $a$ concentrations encountered herein, having hyperspectral fine-resolution data does not lead to any noticeable improvement of the accuracy of chl- $a$ estimation. This is not to imply that hyperspectral data do not provide any advantage over multispectral data for remotely studying the inland, estuarine, and coastal waters. Kutser (2004), for example, used a bio-optical modeling approach with hyperspectral Hyperion data to successfully map the chl-a concentrations in the Gulf of Finland, and illustrated the benefits of using hyperspectral data with high spatial and spectral resolutions. However, algorithms, such as the NIR-red algorithms, which operate on two or three select wavelengths, are not inherently designed to take advantage of the hyperspectral fine-resolution data. For such algorithms, data from sensors such as MERIS with well-positioned spectral channels of reasonably good spectral resolution prove quite sufficient. Hyperspectral optimal estimation approaches that make use of reflectances in the entire 400-750 nm range for estimating constituent concentrations are best suited to take full advantage of the fine-resolution hyperspectral data. It is conceivable that hyperspectral-based optimal estimation approaches can yield similar or perhaps even better accuracies of chl- $a$ estimation in optically complex waters compared to the accuracy provided by the MERIS-based NIR-red algorithms. However, such optimal estimation algorithms are still under development and are not fully operational yet.

Meanwhile, MERIS-based two-band and three-band NIR-red algorithms have proven highly reliable for estimating chl- $a$ concentration in turbid productive waters. However, as noted in previous publications (e.g. Moses et al., 2009a, 2009b), challenges in satellitebased remote estimation of chl- $a$ concentration still remain, chief of which are the within-pixel spatial heterogeneity of water, the effects of atmospheric contribution to the radiance recorded at the sensor, and data quality issues that are inherent to the sensor. It is essential that spurious data resulting from factors such as those mentioned above, especially the residual effects of imperfect atmospheric correction, which can be significant and can cause misleading results, be removed prior to applying the NIR-red algorithms. Nevertheless, the algorithms have so far yielded consistently accurate estimates of chl- $a$ concentration when applied to an extensive set of MERIS data from the Azov Sea and the Taganrog Bay, field spectrometer data from the Chesapeake Bay, Lake Kinneret, and several lakes in Nebraska, and a large dataset of synthetically generated reflectance 


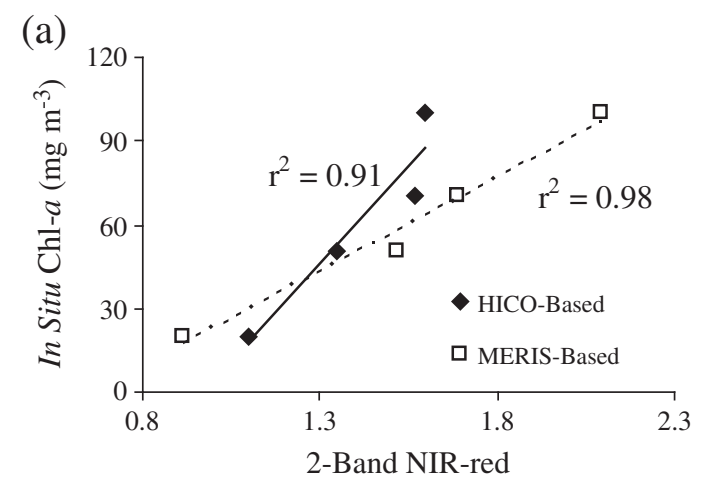

(b)

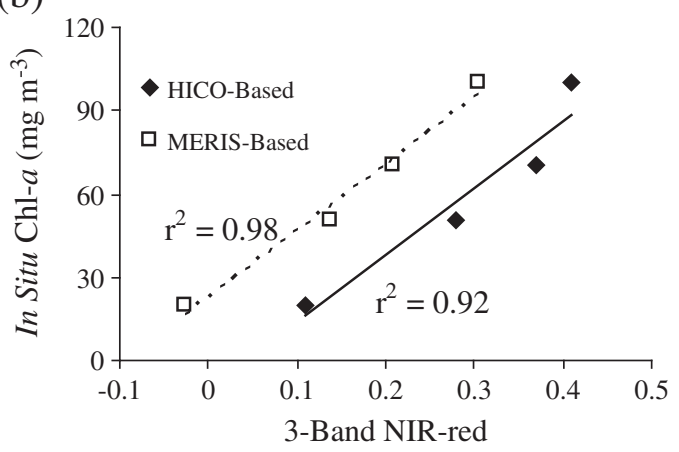

Fig. 6. Comparison between the MERIS-based and the HICO-based NIR-red models for estimating chl- $a$ concentration using the (a) two-band and (b) three-band NIR-red models.

data, without the need for reparameterization (Gilerson et al., 2010; Gitelson et al., 2011a; Gurlin et al., 2011; Yacobi et al., 2011).

It has to be emphasized that the consistent performance of the NIR-red algorithms is dependent on a lack of drastic change in $a_{p h}{ }^{*}$. Moreover, the NIR-red algorithms are inherently meant for turbid productive waters with chl- $a$ concentrations generally above $5 \mathrm{mg} \mathrm{m}^{-3}$. As such, they cannot be expected to perform with similarly consistent accuracies for waters with low chl- $a$ concentrations, say $<5 \mathrm{mg} \mathrm{m}^{-3}$, where the change in $a_{p h}{ }^{*}$ may be drastic (Gilerson et al., 2010).

Nevertheless, the results presented here strongly support the use of MERIS-based two-band and three-band NIR-red algorithms in a routinely operational manner for estimating chl- $a$ concentration in turbid productive waters where $a_{p h}{ }^{*}$ does not vary drastically. More extensive work needs to be done on waters from various geographic locations to analyze the variation of $a_{p h}{ }^{*}$ and the sensitivity of the NIR-red algorithms to the variations in $a_{p h}{ }^{*}$ in order to fully understand and quantify the limits of the potential universal applicability of the NIR-red algorithms.

\section{Acknowledgments}

The authors are thankful to the ESA Earth Observation Missions Helpdesk Team for providing MERIS data. This research was supported by funding from the NASA Land Cover Land Use Program to A. A. Gitelson and in part by the National Research Council (USA) Research Associateship awarded to W. J. Moses via the Naval Research Laboratory.

\section{References}

Aiken, J., \& Moore, G. (2000). ATBD Case 2 s bright pixel atmospheric correction. Report PO-TN-MEL-GS-0005, Vol. 4, U.K.: Center for Coastal \& Marine Sciences, Plymouth Marine Laboratory $14 \mathrm{pp}$.

Borysova, O., Kondakov, A., Paleari, S., Rautalahti-Miettinen, E., Stolberg, F., \& Daler, D. (2005). Eutrophication in the Black Sea region: Impact assessment and causal chain analysis. Global International Waters Assessment. Kalmar, Sweden: University of Kalmar. ISBN:91-89584-50-3.

Carmichael, W. W. (1997). The cyanotoxins. Advances in Botanical Research, 27, 211-256.

Carder, K. L., Chen, F. R., Cannizzaro, J. P., Campbell, J. W., \& Mitchell, B. G. (2004). Performance of the MODIS semi-analytical ocean color algorithm for chlorophyll-a. Climate Change Processes in the Stratosphere, Earth-Atmosphere-ocean Systems, and Oceanographic Processes from Satellite Data, 33(7), 1152-1159.

Dall'Olmo, G., Gitelson, A. A., Rundquist, D. C., Leavitt, B., Barrow, T., \& Holz, J. C. (2005). Assessing the potential of SeaWiFS and MODIS for estimating chlorophyll concentration in turbid productive waters using red and near-infrared bands. Remote Sensing of Environment, 96(2), 176-187.

Dall'Olmo, G., \& Gitelson, A. A. (2005). Effect of bio-optical parameter variability on the remote estimation of chlorophyll-a concentration in turbid productive waters: Experimental results. Applied Optics, 44(3), 412-422.

Darecki, M., \& Stramski, D. (2004). An evaluation of MODIS and SeaWiFS bio-optical algorithms in the Baltic Sea. Remote Sensing of Environment, 89(3), 326-350.

Dekker, A. G. (1993). Detection of Optical Water Quality Parameters for Eutrophic Waters by High Resolution Remote Sensing. Ph.D. Thesis. Amsterdam, Vrije Universiteit: $222 \mathrm{p}$.

Doerffer, R., \& Schiller, H. (2007). The MERIS Case 2 water algorithm. International Journal of Remote Sensing, 28(3-4), 517-535.

Falkowski, P. G., \& Raven, J. A. (1997). Aquatic photosynthesis. Oxford, U.K.: Blackwell Scientific Publishers 375 pp ISBN:0-86542-387-3.

Falkowski, P. G., Scholes, R. J., Boyle, E., Canadell, J., Canfield, D., Elser, J., et al. (2000). The global carbon cycle: A test of our knowledge of Earth as a system. Science, 290(5490), 291-296.

Gao, B. C., \& Davis, C. O. (1997). Development of a line-by-line based atmospheric removal algorithm for airborne and spaceborne imaging spectrometers. SPIE Proceedings, Remote Sensing, 3118. (pp. 132-141).

Gilerson, A., Gitelson, A., Zhou, J., Gurlin, D., Moses, W., Ioannou, I., et al. (2010). Algorithms for remote estimation of chlorophyll-a in coastal and inland waters using red and near infrared bands. Optics Express, 18(23), 24109-24125.

Gitelson, A. (1992). The peak near $700 \mathrm{~nm}$ on radiance spectra of algae and water Relationships of its magnitude and position with chlorophyll concentration. International Journal of Remote Sensing, 13(17), 3367-3373.

Gitelson, A. A., \& Kondratyev, K. Y. (1991). On the mechanism of formation of maximum in the reflectance spectra near $700 \mathrm{~nm}$ and its application for remote monitoring of water quality. Transactions Doklady of the USSR Academy of Sciences: Earth Science Sections, 306, 1-4.

Gitelson, A., Gurlin, D., Moses, W., \& Barrow, T. (2009). A bio-optical algorithm for the remote estimation of the chlorophyll-a concentration in case 2 waters. Environmental Research Letters, 4(045003), 5p.

Gitelson, A., Gurlin, D., Moses, W., \& Yacobi, Y. (2011a). Remote estimation of chlorophylla concentration in inland, estuarine, and coastal waters, Chapter 18. In Q. Weng (Ed.), Advances in environmental remote sensing: sensors, algorithms, and applications (pp. 449-478). : CRC Press, Taylor and Francis Group, 610 p. ISBN:9781420091755.

Gitelson, A. A., Gao, B. C., Li, R. R., Berdnikov, S., \& Saprygin, V. (2011b). Estimation of chlorophyll-a concentration in productive turbid waters using a Hyperspectral Imager for the Coastal Ocean - The Azov Sea case study. Environmental Research Letters, 6(024023), doi:10.1088/1748-9326/6/2/024023 6 pp.

Gons, H. J. (1999). Optical teledetection of chlorophyll a in turbid inland waters. Environmental Science and Technology, 33(7), 1127-1132.

Gower, J. F. R., Doerffer, R., \& Borstad, G. A. (1999). Interpretation of the $685 \mathrm{~nm}$ peak in water-leaving radiance spectra in terms of fluorescence, absorption and scattering, and its observation by MERIS. International Journal of Remote Sensing, 20(9), 1771-1786.

Gurlin, D., Gitelson, A. A., \& Moses, W. J. (2011). Remote estimation of chl- $a$ concentration in turbid productive waters - Return to a simple two-band NIR-red model? Remote Sensing of Environment, 115(12), 3479-3490.

Han, L. H., \& Rundquist, D. C. (1997). Comparison of NIR/RED ratio and first derivative of reflectance in estimating algal-chlorophyll concentration: A case study in a turbid reservoir. Remote Sensing of Environment, 62(3), 253-261.

Honeywill, C., Paterson, D. M., \& Hegerthey, S. E. (2002). Determination of microphytobenthic biomass using pulse-amplitude modulated minimum fluorescence. European Journal of Phycology, 37(4), 485-492.

Jeffrey, S. W., \& Humphrey, G. F. (1975). New spectrophotometric equations for determining chlorophylls $a, b, c 1$ and $c 2$ in higher plants, algae and natural phytoplankton. Biochemie und Physiologie der Pflanzen, 167, 191-194.

Korwan, D. R., Lucke, R. L., Corson, M., Bowles, J. H., Gao, B. C., Li, R. R., et al. (2010). The Hyperspectral Imager for the Coastal Ocean (HICO) - Design and early results. IGRSS Workshop on Hyperspectral Image and Signal Processing: Evolution in Remote Sensing (WHISPERS, 2010), 14-16 June 2010 (pp. 1-4)., doi: 10.1109/WHISPERS.2010.5594935.

Kutser, T. (2004). Quantitative detection of chlorophyll in cyanobacterial blooms by satellite remote sensing. Limnology and Oceanography, 49(6), 2179-2189.

Le, C., Li, Y., Zha, Y., Sun, D., Huang, C., \& Lu, H. (2009). A four-band semi-analytical model for estimating chlorophyll a in highly turbid lakes: The case of Taihu Lake, China. Remote Sensing of Environment, 113(6), 1175-1182.

Levin, I., Levina, E., Gilbert, G., \& Stewart, S. (2005). Role of sensor noise in hyperspectral remote sensing of natural waters: Application to retrieval of phytoplankton pigments. Remote Sensing of Environment, 95(2), 264-271.

Leppäkoski, E., Shiganova, T., \& Alexandrov, B. (2009). European enclosed and semienclosed seas. Biological invasions in marine ecosystems. In G. Rilov, \& J. A. Crooks (Eds.), Ecological Studies (Series), Vol. 204. (pp. 529-547), doi:10.1007/978-3540-79236-9 $641 \mathrm{pp}$ 
Lucke, R. L., Corson, M., McGlothlin, N. R., Butcher, S. D., Wood, D. L., Korwan, D. R, et al. (2011). Hyperspectral Imager for the Coastal Ocean: Instrument description and first images. Applied Optics, 50(11), 1501-1516.

Matishov, G. (2005). System approach to the water quality and bioproductivity of the Azov Sea basin. In C. A. Brebbia (Ed.), River Basin Management III; WIT Transactions on Ecology and Environment, Vol. 83. (pp. 347-357) 672 p. ISBN:1-84564-023-3.

Mobley, C. D. (1989). A numerical model for the computation of radiance distributions in natural waters with wind roughened surfaces. Limnology and Oceanography, 34, 1473-1483.

Mobley, C. D. (1994). Light and water: Radiative transfer in natural waters. San Diego, California: Academic Press Inc. 592 p.

Mobley, C. D., \& Sundman, L. K. (2008). Hydrolight 5 Ecolight 5 technical documentation (1st Ed.). Bellevue, WA: Sequoia Scientific Inc.

Moore, G. F., Aiken, J., \& Lavender, S. J. (1999). The atmospheric correction of water colour and the quantitative retrieval of suspended particulate matter in Case II waters: Application to MERIS. International Journal of Remote Sensing, 20(9), 1713-1733.

Morel, A., \& Prieur, L. (1977). Analysis of variations in ocean color. Limnology and Oceanography, 22(4), 709-722.

Moses, W. J. (2009). Satellite-based estimation of chlorophyll-a concentration in turbid productive waters. PhD Diss., University of Nebraska-Lincoln, Lincoln, NE, USA.

Moses, W. J., Gitelson, A. A., Berdnikov, S., \& Povazhnyy, V. (2009a). Estimation of chlorophyll-a concentration in case II waters using MODIS and MERIS dataSuccesses and challenges. Environmental Research Letters, 4(045005) 8 pp.

Moses, W., Gitelson, A., Berdnikov, S., \& Povazhnyy, V. (2009b). Satellite estimation of chlorophyll-a concentration using the red and NIR bands of MERIS - The Azov Sea case study. IEEE Geoscience and Remote Sensing Letters, 4(6), 845-849.
Moses, W. J., Bowles, J. H., Lucke, R. L., \& Corson, M. R. (2012). Impact of signal-tonoise ratio in a hyperspectral sensor on the accuracy of biophysical parameter estimation in case II waters. Optics Express, 20(4), 4309-4330.

Revenga, C., \& Kura, Y. (2003). Status and trends of biodiversity of inland water ecosystems. Montreal: Secretariat of the Convention on Biological Diversity.

Ruddick, K. G., Gons, H. J., Rijkeboer, M., \& Tilstone, G. (2001). Optical remote sensing of chlorophyll-a in case 2 waters by use of an adaptive two-band algorithm with optimal error properties. Applied Optics, 40(21), 3575-3585.

Schalles, J. F., Gitelson, A. A., Yacobi, Y. Z., \& Kroenke, A. E. (1998). Estimation of chlorophyll a from time series measurements of high spectral resolution reflectance in a eutrophic lake. Journal of Phycology, 34(2), 383-390.

Schiller, H., \& Doerffer, R. (1999). Neural network for emulation of an inverse model Operational derivation of Case II water properties from MERIS data. International Journal of Remote Sensing, 20(9), 1735-1746.

Stumpf, R. P., \& Tyler, M. A. (1988). Satellite detection of bloom and pigment distributions in estuaries. Remote Sensing of Environment, 24(385-404).

Vasilkov, A., \& Kopelevich, O. (1982). Reasons for the appearance of the maximum near $700 \mathrm{~nm}$ in the radiance spectrum emitted by the ocean layer. Oceanology, 22(6), 697-701.

Yang, W., Matsushita, B., Chen, J., Fukushima, T., \& Ma, R. (2010). An enhanced threeband index for estimating chlorophyll-a in turbid case-II waters: Case studies of Lake Kasumigaura, Japan, and Lake Dianchi, China. IEEE Geoscience and Remote Sensing Letters, 7(4), 655-659.

Yacobi, Y. Z., Moses, W. J., Kaganovsky, S., Sulimani, B., Leavitt, B. C., \& Gitelson, A. A. (2011). NIR-red reflectance-based algorithms for chlorophyll-a estimation in mesotrophic inland and coastal waters: Lake Kinneret case study. Water Research, 45(7), 2428-2436. 